\title{
Civil and Political Rights
}

\section{Stephen Xu, Ottawa-Carleton District School Board Student Trustee}

\section{Context}

Youth are very energetic and creative with our new ideas and suggestions. Youth are not hesitant to propose new pedagogies, such as instituting oral testing to replace the conventional standardized testing. As a result of our imaginative approaches, youth are often criticized for their pragmatism and in some cases, their naivety. Consequently, youth can easily become discouraged, leading to the creation of one paradigmatic obstacle.

Common Obstacle - Most youth are convinced that they have no influence on those with decision-making powers.

The Common Obstacle leaves youth with the impression that to share their ideas would be futile. Ultimately, this leads to self-suppression, inciting all youth to hold their tongues about their ideas.

Nevertheless, there are countless examples where youth ideas have succeeded in not only finding themselves on decision-making tables, but also becoming the hot topic of the discussion.

\section{Example 1}

Recently, at Bell High School, students and teachers came together to voice their concerns surrounding various safety concerns at the site's science labs. Through a rapid consultation process, a motion was passed, leading to a number of infrastructure refurbishments, valued at over $\$ 6000$. Specifically through the student voice, students were able to use their position as the first-hand users of the facilities to strongly express the safety risks.

\section{Example 2}

The Ottawa-Carleton District School Board recognizes the importance of student voice within the education system. To truly embody this, the school board is developing a Student Voice Policy through ample discussions with students. The policy would outline the various platforms that students could utilize to amplify their student voice and ensure that those with decision-making powers hear it. 


\section{Example 3}

Following the City of Ottawa Mayor's Youth Summit, a Youth Summit Action Plan document was devised. It is comprised of over 30 objectives seeking to improve youth well being in Ottawa by increasing employment opportunities to creating services tailored to the youth demographic. With specific indicators for each goal, the City of Ottawa is progressing well. These can be found at http://ottawa.ca/en/youth-summitaction-plan.

In these three examples, it is clear that people want to hear the youth voice, and are more than willing to work with us to better the well being of youth within education and the City of Ottawa.

\section{Solution}

By noting the large number of cases where youth have successfully influenced those with decision-making powers, youth must grow to become resilient and continue to share their constructive and revolutionary ideas.

\section{Final Thoughts}

Progress and reform are two very different concepts. The first embodies an idea of advancement towards a vision or goal. However, should the vision or goal be convoluted, or even misguided, then the 'progress' itself lacks direction. In contrast, reform intertwines both advancement but with direction in the right bearing.

Reform can only be obtained with groundbreaking ideas that often take the fresh eyes of the youth to invent. Use your voice, because you are not the only one who wants to hear it. 